\title{
BOSQUEJO DE LA TEORÍA CONTRACTUAL Y DE LA REVOLUCION
}

\author{
Filadelfo Linares
}

\section{Introducción}

La teoría contractual, que quiere fundar el Estado, parte en verdad de un Estado real, del existente, del cual saca el modelo (formal).

En el Estado real se conciertan pactos, se hacen contratos. Eso supone que el Estado tiene un derecho que le sirve de soporte a esos pactos o contratos y los hace obligatorios. Este derecho, en el Estado real, es el derecho estatal, el Derecho Civil, el Derecho Contractual.

Ahora bien, así como en el Estado real se hacen contratos o se conciertan pactos, así también se hacen o se conciertan en el Estado que hay que fundar, del cual es modelo (formal) el real. ${ }^{1} \mathrm{Y}$ así como sucede en el Estado real, sucede también en éste: un derecho debe existir, que soporte y haga obligatorio el Contrato Social. Dado que este contrato o pacto se concierta en el estado de naturaleza, en el estado pre-estatal, es el derecho que lo soporta y hace obligatorio, el Derecho Natural, el ius naturale.

En el Estado ya fundado, o sea en el Estado real (literario), no puede concertarse naturalmente un Contrato Social. Lo que en él puede concertarse, es un Herrschaftsvertrag, un pactum subjectionis, un Pacto o Contrato de Gobierno.

El Pacto o Contrato de Gobierno implica una transferencia de poder, del poder originario y por tanto soberano. Esta transferencia puede ser una incondicional o una condicional. En la forma impura y conservadora del Contrato, como se presenta en Hobbes, por ejemplo, esa transferencia es incondicional. La transferencia condicional se da en la forma pura y revolucionaria del Contrato.

I "Sie (la teoría contractual, FL) nimmt einèn oder mehrere Sätze einer feststehenden staatlichen Rechtsordnung, um aus ihr den Staat herzuleiten, was nichts anderes

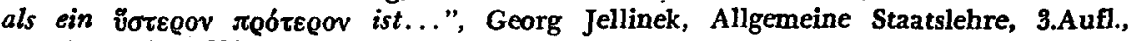
p. 216. Berlin, 1922. 
Anticipando el final, digámoslo aquí: Ni Locke ni Rousseau admiten un pactum subjectionis en el Estado. "Il n'y a qu'un contract dans l'État, c'est celui de l'association...", dice Rousseau taxativamente. ${ }^{2}$

Es decir que, según esa concepción, el pueblo, resultante del Contrato Social o "... acte par lequel un peuple est un peuple, ${ }^{3}$ retiene la soberanía, "l'autorité souveraine"," y la retiene en virtud del consensus iuris del "acte d'association"."

Mas, resulta que, para que la soberanía sea efectiva, tiene que ser delegado en un regente el derecho a ejercerla: “. . c c'est proprement ce droit", dice Rousseau, "indispensable pour faire vivre et mouvoir le corps politique, que le souverain donne au prince en instituant le gou-

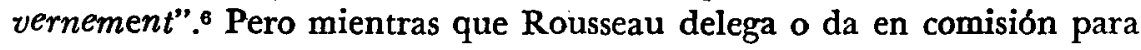
su ejercicio sólo una parte de la soberanía, a saber, el poder ejecutivo, delega Locke todo el poder supremo ("the supreme power"), tanto el legislativo como el ejecutivo. Es claro que la delegación o comisión, en ambos casos, es hecha bajo condición resolutoria.

Concluyamos la Introducción diciendo que el Contrato Social, que ha comenzado a ocuparnos ya, se presenta históricamente como un cuestionamiento del poder político real (el del gobierno monárquico) a favor de un poder político ideal (el del pueblo).

\section{Comienzos literarios de la teoria contractual}

Los comienzos literarios de la teoría contractual, en su forma secular, están en Grecia, como un producto del desgajamiento del individuo del cuerpo politico común, de la polis. Y se presenta como un cuestionamiento de los valores e ideas tradicionales, se forma especialmente de un enfrentamiento de la púous con el vópos, con la tendencia a rehabilitar la púous a expensas del vónos, haciendo aparecer para ello las pres-

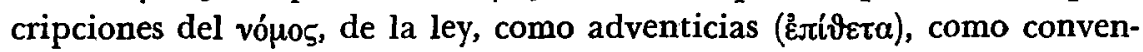
cionales, como no naturales, sino producto de un convenio o contrato, a diferencia de las prescripciones de la púøı o naturaleza que son innatas al hombre, ${ }^{7}$ exentas por tanto de artificialidad y al margen del capricho de los hombres y de las conveniencias pasajeras. Planteado eso en términos políticos, es el enfrentamiento del estado de naturaleza con

2 Jean-Jacques Rousseau, Du contract social, p. 138. Edit. Garnier-Flammarion. París, 1966.

3 Ibid.,p. 50.

4 Ibid. p. 52.

s Ibidem.

- Ibid., p. 137.

7 Cf. Antifón, en J. W. Gough, The Social Contract, p. 11. Oxford, 1957. 
el estado civil. Ese enfrentamiento es la expresión de una crisis de la sociedad, presentándose el estado de naturaleza con sus valores permanentes como pauta para solucionar esa crisis.

Al desmitificar el vónos, la ley, presentándolo como un contrato ( $\delta$

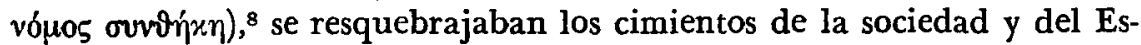
tado, exponiendo a éstos a su disolución.

Un ataque semejante a la sociedad y al Estado, no podía provenir sino de aquellos que habían roto con la tradición y que se habían colocado por tanto al margen de la sociedad de su tiempo. Ese es el caso de los sofistas.

Los pioneros en ese respecto son los sofistas Antifón y Licofrón, habiendo sido este último inmortalizado por Aristóteles al mencionarlo en su Politica (1280 b8).

Pero políticamente más importante que estos sofistas es el sofista Calicles. No obstante que Calicles no habla explícitamente del carácter contractual de la ley, ni tampoco explícitamente del Contrato Social, implícitamente está eso presente en su pensamiento expuesto en el diálogo Gorgias de Platón:

.. Según la naturaleza, todo lo peor es también lo más feo; por consiguiente, sufrir una injusticia es una cosa muy fea, pero según la ley, más feo es aún el cometerla. $Y$ en efecto, sucumbir a la injusticia de otro no es propio de un hombre sino de un vil esclavo, para quien vale más morir que vivir, cuando sufriendo injusticias y ofensas no se está en estado de defenderse uno mismo ni tampoco defender a quienes le son caros. Pero pienso en que los que escriben las leyes son débiles y la gran masa, y teniendo sólo en cuenta lo que les puede interesar, determinan lo que ha de ser digno de loa y lo que ha de merecer ser prohibido. Para amedrentar a los más fuertes, que podrían ir más allá de los otros e impedírselo, dicen que es feo e injusto aventajar en algo a los demás, y que trabajar por hacerse más poderosos es hacerse culpables de injusticia, porque siendo los más débiles se consideran demasiado felices de que todos sean iguales, ya que ellos son los peores. Tal es la razón por la cual en el orden de la ley es injusto y feo el querer aspirar a más que la mayoria y por esto se le ha dado el nombre de injusticia. Pero me parece que la naturaleza demuestra que no es justo que el que valga más tenga menos que otro que no vale lo que él y el más fuerte menos que el más débil, y prueba en mil ocasiones que debe ser así tanto en lo que concierne a los animales como a los mismos hombres, entre los cuales vemos Estados y naciones enteras donde la regla de lo justo es que el más fuerte se imponga al más débil y esté más beneficiado que él...

8 Cf. Licofrón, en J. W. Gough, op. cit., p. 12. 


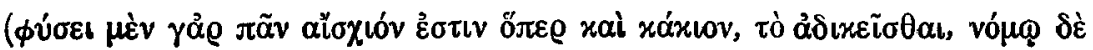

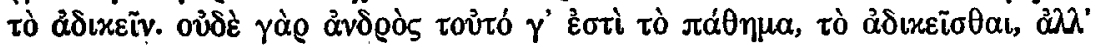

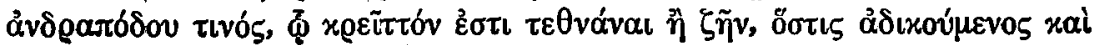

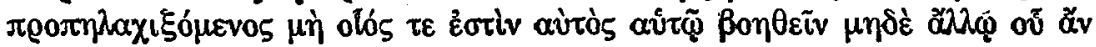

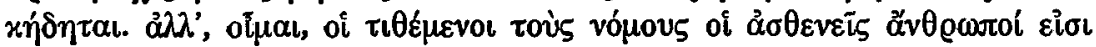

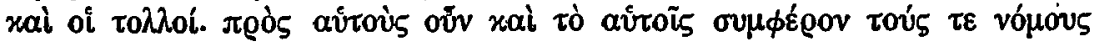

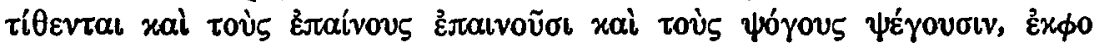

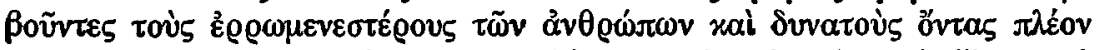

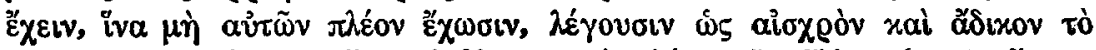

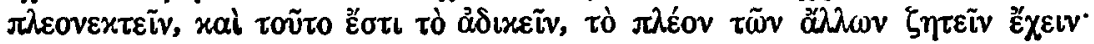

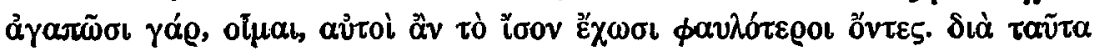

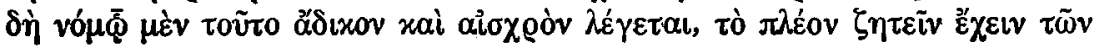

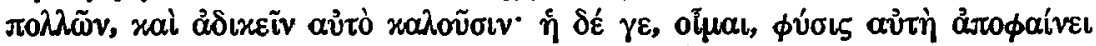

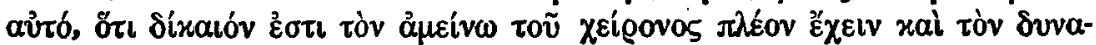

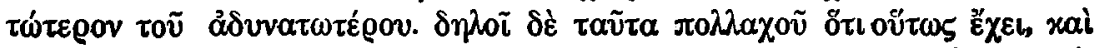

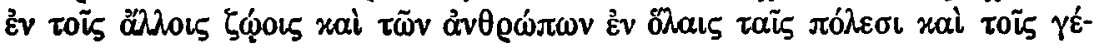

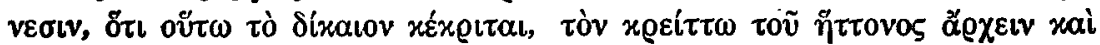

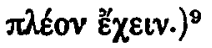

Calicles nos muestra, pues, la ley, producto de la convención, como algo negativo, que no tiene por qué ser acatado, algo que debe ser combatido. Y como esa ley es la expresión del Estado, con el ataque a ella se ataca a éste. No obstante que el pensamiento de Calicles es elitesco, es de utilidad revolucionaria en cuanto que es apropiado para correr la autoridad estatal, para socavar los fundamentos del Estado. Calicles, además, combate el derecho estatal con el derecho natural. En principio, es lo mismo que harán los pensadores revolucionarios de la teoría contractual.

Calicles nos dice que los más débiles se ven obligados a inventar las leyes para protegerse de los más fuertes. Eso supone que antes de que aconteciera eso, los hombres vivían en un desierto jurídico, en un estado de naturaleza, en el status naturalis, donde regía sólo la "ley" del más fuerte, donde el más fuerte se le imponía al más débil, donde los débiles eran las víctimas de los fuertes, donde no se había alcanzado aún ni siquiera el estadio de la lucha de todos contra todos, del bellum omnium contra omnes, en el que cada uno tiene el derecho a todo. El estado en que se vivía era de un total desamparo para los débiles, un estado de explotación y de opresión de los débiles. Y como los débiles se dan cuenta de que una lucha contra los fuertes sería inútil, que no la ganarian, ni en un cuerpo a cuerpo ni bando a bando, tanto por ser éstos

8 Platón, Gorgias 483 a, b, c, d. The Loeb Classical Library. Traducción Colección Austral, Buenos Aires, 1966, p. 187. 
más fuertes que ellos como por tener las mejores armas, condición adicional de la superioridad, entonces se les ocurre inventar las leyes, leyes no destinadas ciertamente a vencer a los más fuertes, pero sí a neutralizarlos, a obligarlos a un fair play, a la convivencia. Las leyes se constituyen en árbitro entre los más débiles y los más fuertes. Esa salida constituía evidentemente una especie de Contrato Social.

Esta perspectiva es sin embargo unilateral. Que la iniciativa haya partido de los débiles, es comprensible. Los fuertes o más fuertes no tenían urgencia alguna de tomarla. Aquí es aplicable el pensamiento de Rousseau: "Il est raisonnable de croire qu'une chose a été inventée par ceux à qui elle est utile, plutôt que par ceux à qui elle fait tort". ${ }^{10}$ Pero Rousseau dice eso pensando más que todo en Trasímaco, según el cual, la parte más fuerte inventa las leyes para su propio provecho, o dicho con las propias palabras de Trasímaco en el diálogo de Platón La República:

Yo sostengo, lo sostengo, sí, que la justicia no es otra cosa sino el interés del más fuerte... ¿Y acaso todo Gobierno no establece las leyes en vista de su interés particular, democráticas las democracias, monárquicas las monarquías y lo mismo los demás regímenes? Además, una vez hechas estas leyes, proclaman como justo para los gobernados lo que está en su propio interés, y si alguno falta a ellos, le castigan como violador de la ley y de la justicia. He aquí, pues, mi excelente amigo, lo que yo pretendo que es la justicia en todos los Estados: el interés del Gobierno constituido: es decir, del más fuerte. De donde resulta para todo hombre capaz de razonar como es debido que en todas partes la justicia y el interés del más fuerte son una y la misma cosa.

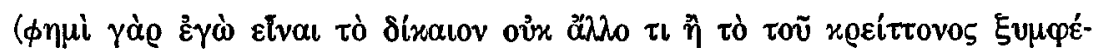

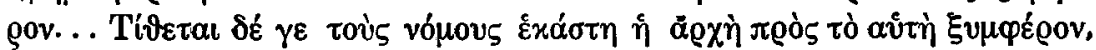

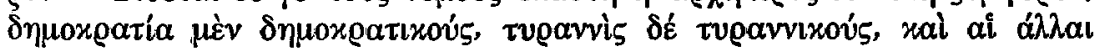

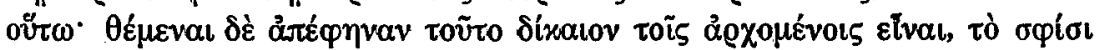

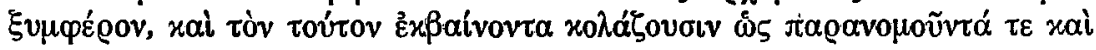

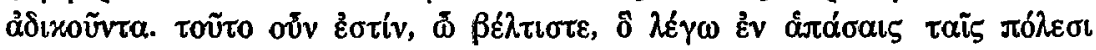

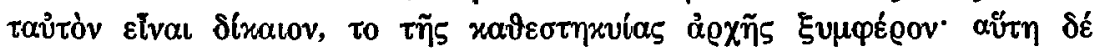

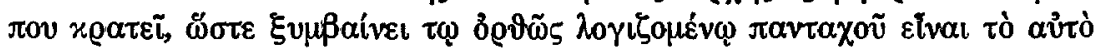

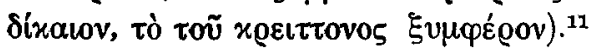

$10 \mathrm{~J}$. J. Rousseau, Discours sur l'origine de l'inégalité, p. 80. Edición conjunta con Du contrat social hecha por Classiques Garnier, Paris, 1962.

11 Platón, Politeia 338c, e, 339a. La República, pp. 79-80. Traducción de Juan B. Bergua. Ediciones Ibéricas, Madrid, 1959. Dejamos en pie la expresión "lo sostengo, s'", aunque no está en el original, como una libertad retórica.

Fl original de La Repuiblica es el de la Colección The Loeb Classical Library. 
Con todo, como el mismo Rousseau admite que el concepto de fuerte o de débil es un concepto relativo: quien es fuerte políticamente, por ejemplo, puede ser débil económicamente, y a la inversa: quien es fuerte económicamente puede ser débil políticamente, el pensamiento anterior de Rousseau encaja conceptualmente tanto en un caso (la concepción de Calicles) como en el otro (la concepción de Trasímaco).

Pero lo que no ha sido puesto aún en claro explícitamente, es la razón que han tenido los más fuertes para aceptar la innovación hecha por los más débiles: las reglas del juego comunes: las leyes. La razón que hayan tenido pues para dejarse entrabar el poder natural que tenían. Una razón puede haber sido, como sugiere Hobbes, de orden físico: "For as to the strength of body, the weakest has strength enough to kill the strongest, either by secret machination, or by confederacy with others, that are in the same danger with himself". ${ }^{12}$ Otra razon y no menos fuerte, puede haber sido, como diria Rousseau, el deseo de darle carácter legal a lo que poseían, es decir: de transformar la posesión en propiedad.

Contrariamente a Trasímaco, cuyo pensamiento no contiene elementos contractuales, ${ }^{13}$ Glaucón, el joven hermano de' Platón, habrá de conducirnos directamente a la teoría contractual, al Contrato Social. La transmisión de la primera idea orgánica del Contrato Social que se conozca en la Historia, estará, pues, a su cargo. Glaucón, sin embargo, no es sofista. El actúa simplemente de expositor del ideario sofista en esa materia, tomando como base la definición de la naturaleza y del origen de la justicia. Glaucón nos dice, pues:

Suele decirse que, de acuerdo con la naturaleza, cometer la injusticia es un bien; sufrirla, un mal, y que es mayor el daño cuando se la sufre que el bien cuando se la comete. Por ello, cuando los hombres se hacen y soportan injusticias mutuamente, experimentando, como es lógico, placer o dolor, lo que unos y otros, por supuesto, no pueden impedir o evitar, respectivamente, piensan que es útil entenderse entre sí con objeto de no cometer ni sufrir en adelante la injusticia. De aquí tomaron nacimiento las leyes y los acuerdos de los hombres entre sí, y las prescripciones legales fueron llamadas legalidad y justicia. Tal es el origen y esencia de la justicia. Justicia que ocupa el medio entre el bien mayor: impunidad en la injusticia, y el mayor mal: impotencia de vengarse de la injusticia. Colocada entre ambos extremos, no es la justicia amada como un bien, sino honrada a causa de la impotencia en que suele estarse de cometer la injusticia. Pues el que puede cometerla y se siente verdaderamente hom-

12 Thomas Hobbes, Leviathan, p. 63. Everyman's Library, núm. 691.

13 J. W. Gough, op. cit., p. 10. 
bre, se guardaría muy bien de hacer un convenio con objeto de suprimir la injusticia, tanto cometida como sufrida. Locura seria tal cosa de su parte. Aquí tienes, Sócrates, cuál es la naturaleza y el origen que se le suele dar. ${ }^{14}$

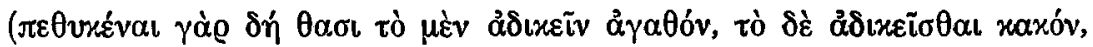

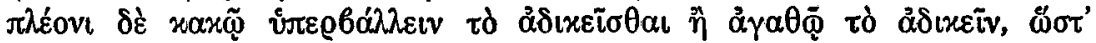

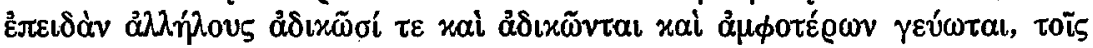

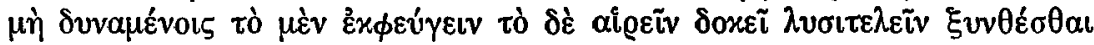

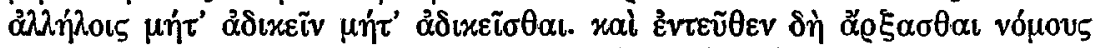

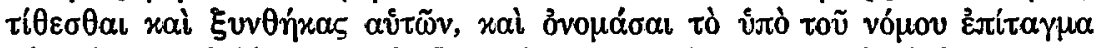

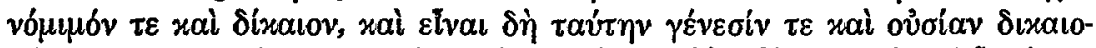

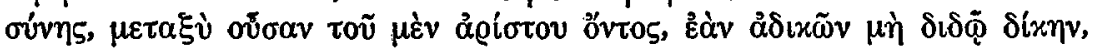

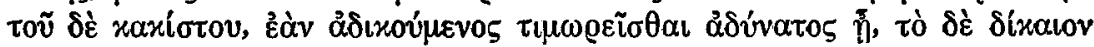

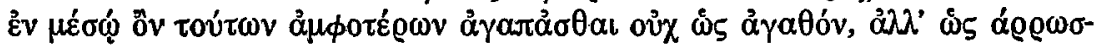

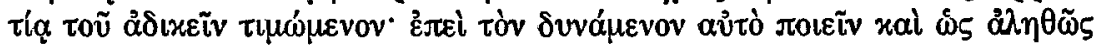

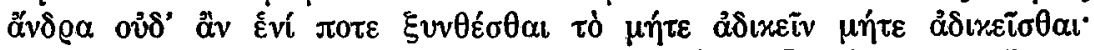

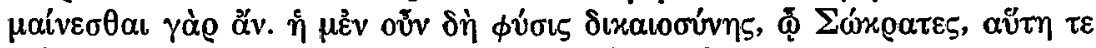

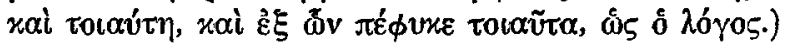

Como en el estado de naturaleza no se puede dañar impunemente, como ahí la capacidad de dañar sin ser dañado no es ilimitada, como ahí el mismo derecho que tengo yo de dañar a otro lo tiene el otro de dañarme a mi, como ese estado es evidentemente insatisfactorio y riesgoso, por eso la razón les sugiere a los hombres asociarse, ponerse de acuerdo en un modus vivendi que les dé seguridad, que los proteja de sí mismos. Ese acuerdo es el Contrato Social.

La cuestión a elucidar aquí sería la de por qué es necesario en general un Contrato Social, la de por qué tengan necesidad los hombres de someterse a una instancia superior, la de las leyes, restringidora de su libertad natural, como única garantía de paz y por tanto de preservación de la vida y de los bienes. La explicación de Platón, que ha hecho escuela, desconsuela:

Es necesario que los hombres se hagan leyes y que vivan de acuerdo con ellas porque de lo contrario no se diferenciarían en nada de las bestias más salvajes.

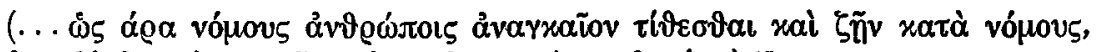

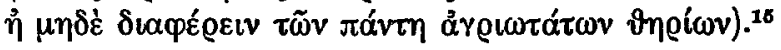

14 Platón, Politeia, 358e-359 a,b. Traducción: ibid., p. 107.

15 Platón, Nomoi (Las Leyes), 874e-875a. Edic. I. Burnet. Oxford. En la traducción hemos seguido a Hieronymus Müller. 
Platón se ve precisado a explicar esa desconfianza en el buen sentido del hombre, en el buen uso de su razón. Y como Platón dice eso en conexión con la construcción de un nuevo Estado, la explicación es política:

La razón de eso es, que la naturaleza de los hombres no es naturalmente capaz de darse cuenta de lo que es beneficioso para la vida de ellos en el Estado, ni, aun dándose cuenta de ello, ser capaz de ponerlo en práctica voluntariamente.

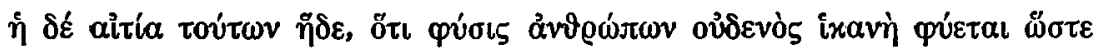

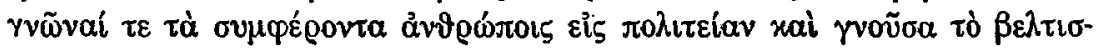

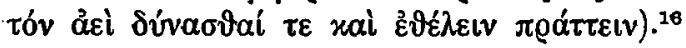

Siguiendo a Platón, también Aristóteles duda del buen sentido de los hombres, de su capacidad natural de convivencia, de que en los actos humanos prepondere la razón. $\mathrm{Y}$ precisamente eso hace necesarias las leyes:

Así como el hombre en su perfección es el más noble de los animales, así es él el peor de todos cuando no está sujeto a la ley y al derecho.

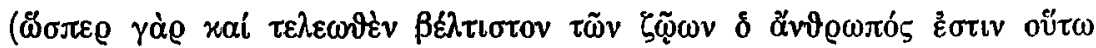

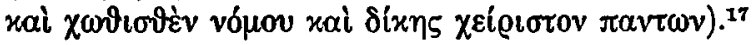

La explicación de Aristóteles a esa sinrazón reza:

No hay peor injusticia que la que posee armas. Las armas naturales que tiene el hombre en sus manos son la inteligencia y la voluntad apropiadas mayormente para hacer un uso opuesto al bueno.

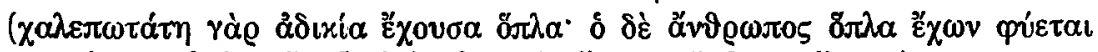

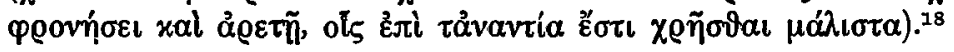

Digámoslo aquí de paso: Ese hombre sin leyes o en estado de naturaleza considerado por Platón como la más peligrosa de las fieras, adquirirá más tarde en Hobbes la forma del lupus, del lobo feroz. Haciendo suya una expresión de su amigo Francis Bacon, dirá Hobbes,

16 Ibid., 875a.

17 Aristóteles, Politica, 1253 a 30f; W. D. Ross (Oxford). En la traducción hemos seguido a Franz Susemihl.

18 Aristóteles, ibidem. 
que en el estado de naturaleza, donde la única "norma" es imponer los propios deseos o caprichos, sin piedad alguna (contrariamente a lo que pensará más tarde Rousseau), que en ese mundo pues el hombre es lobo para el hombre: Homo homini lupus(est).

Es claro que un estado semejante, en que cada individuo se cree con el derecho natural de apoderarse de todo y de subyugar a los demás, no puede dar lugar sino a una guerra de todos contra todos, a un bellum omnium contra omnes.

¿Por qué es ello así? ¿Por qué esa desconfianza en el hombre, en la naturaleza humana? ¿Lo hace Hobbes, como insinúa Carl Schmitt, para justificar el tutelaje del hombre, la puesta en hierros de su libertad? Independientemente de las intenciones políticas de Hobbes, dirigidas a estabilizar el triunfo de la revolución puritana de Cromwell y la paz interior del nuevo "commonwealth" 19 mediante un Estado fuerte, absolutista y totalitario, su desconfianza en la naturaleza humana no es política, sino religiosa, puritana, a lo cual le sirve de soporte su psicología, que recuerda a la de Platón.

En efecto, el estado de naturaleza exterior es un reflejo del estado de naturaleza interior. $Y$ es que el alma humana no está compuesta solamente de una parte, de la parte racional, de la razón pues, sino también de una parte irracional, la predominante, la parte concupiscente, el mundo de las pasiones, en las que se destaca el deseo de poder y de gloria. $\mathrm{Y}$ es precisamente en esta parte donde se funda el estado de naturaleza, es justamente esta parte la que constituye ese estado. En este estado cada individuo reclama para sí el derecho en su totalidad.

Una lucha se da pues en el alma, en el interior del hombre, entre las pasiones y la razón. Ahora bien, si esta lucha quedara restringida al interior del hombre, poco motivo de preocupación daría, socialmente. Pero resulta que el hombre que vive en pleito consigo mismo, difícilmente vive en armonía con los demás. Esa lucha en el interior de cada individuo, bajo el signo del deseo de poder y de gloria, se proyecta entonces, inevitablemente, al exterior, al mundo, dando lugar allí a un bellum omnium contra omnes, a una guerra de todos contra todos. ${ }^{20}$

La parte irracional del alma, la parte concupiscente, es la más fuerte. De ahí la desconfianza de Platón y de Aristóteles y de Hobbes en la naturaleza humana. Con todo, la parte racional no capitula ante la irracional, no se resigna, no opta por la pasividad. Ella le hace ver al hombre que sólo una renuncia de todos y cada uno a todo, que sólo un freno al deseo de poder y de gloria, puede darle seguridad a su vida

10 Eso no excluye el que haya servido también indirectamente a los intereses de la burguesía capitalista o del "individualismo posesivo" (Macpherson).

20 La guerra de los capitalistas entre sí, dirfa Marx. 
y a sus bienes. En su esfuerzo persuasivo, la razón se ve auxiliada por un sentimiento especial, más racional que pasional, por el fear of Death, por el miedo a la muerte. El hombre, entonces, le da oídos a la razón. $\mathrm{Y}$ es así como los hombres deciden hacer un pacto, un covenant o contrato, poniendo como garante de éste a un tercero. Ese pacto o contrato es uno muy especial, una mezcla de pactum societatis y de pactum subjectionis, limitando este último a los contratantes. De ese pacto o contrato, en que cada uno renuncia a su derecho individual, a todo, resulta el tercero en cuestión, un poder común, un "common power" o espada ("sword"), sin la cual el pacto o contrato seria una mera palabra ("word"). Ese poder común es el Estado, el Common-Wealth o Leviatán, dueño y señor de la libertad y de los derechos de los individuos. Un monstruo marino o cocodrilo, al que, por ser su poder absoluto, Hobbes prefiere llamar, "reverentemente", deus mortalis, "a mortal god", un dios mortal. $^{21}$

Ese Leviatán, legislador y ejecutor de las leyes, no está sujeto a éstas, es por tanto legibus solutus. Esta característica del Leviatán, fundada históricamente en la lex regia de los romanos, tiene ya en Platón un modelo. Es el modelo del "politikós", del "Estadista", en el diálogo del mismo nombre. Efectivamente, también el "politikós" legisla y ejecuta las leyes, y las acata él mismo si quiere, y si no, no; es también, por tanto, legibus solutus, y por lo mismo "similar a Dios".

Pero mientras que Platón, abandonando la esperanza de que un personaje como el "politikós" pueda darse en la tierra, hace de las leyes el poder soberano, ${ }^{22}$ Hobbes erige al Leviatán en soberano absoluto.

\section{En torno de la terminologia contractual}

El estado de naturaleza, bajo el 'punto de vista que se lo considere, es un estado de imperfección y de inseguridad, en grado mayor (Hobbes) o en grado menor (Locke, Rousseau). Como ése es un estado de individualistas, se sale de él solamente cuando los individuos ven en la sociedad o en lo que ella representa, la mejor forma de promover y de proteger sus intereses individuales. La salida es el Contrato Social.

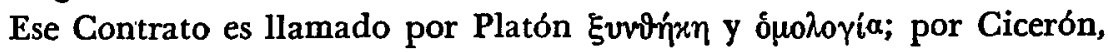
pactio (también, en cierto sentido, consensus iuris o vinculum iuris); $;^{28}$

21 En esta exposición del pensamiento de Hobbes hemos utilizado tanto el artf́culo sobre éste de la Encyclopedia of Philosophy, vol. 4, como el propio Leviatán de Hobbes, en la edición de la Everyman's Library, núm. 691.

22 Cf. sobre este tema nuestro libro Der Philosoph und die Politik. Edit. Anton Hain. Meisenheim/Alemania, 1972.

${ }_{23}$ “...il vinculum, iuris si risolve nel vincolo contrattuale, ossia ritrova il suo 
por San Agustín, pactum. En la Edad Moderna, es llamado también pactio, como Cicerón. Así lo llama, por ejemplo, Mario Salamonio, quien es considerado como el autor en que se da la "prima enunciazione della teoria del contratto sociale inteso come pactum societatis", 24 es decir, como un contrato "intercorso fra tutti $i$ componenti la collettività...".25 Hobbes llama el Contrato covenant; Locke, compact; Rousseau lo llama pacte d'association, asimismo pacte social, siendo sin embargo el título de su libro El Contrato Social (Du Contrat Social) el que habría de devenir la denominación genérica.

No obstante la denominación genérica de Contrato Social, éste se divide en dos especies o partes constitutivas: la propiamente social y la propiamente política. La parte social, como salida al estado de naturaleza, es la llamada pactum societatis. De este pactum societatis o pactum unionis, como también se dice, nace la sociedad civil (Locke) o el pueblo (Rousseau), ambos con el sentido de Estado. Este Estado, sinónimo del pactum societatis, no implica sin embargo un ejecutor o Gobierno. En Locke no lo implica, en Rousseau tampoco, ni tampoco en Hobbes. En alemán se expresa esa unidad como Gesellschafts-und Staatsvertrag, ${ }^{26}$ diferenciándosela del otro momento del Contrato, el llamado pactum subjectionis o Pacto de Gobierno, Herrschaftsvertrag. En Hobbes, y ya esto lo hemos insinuado, se dan ambas especies: el pactum societatis es al mismo tiempo un pactum subjectionis entre los mismos contratantes. El Estado no resulta en Hobbes ni directamente del pactum societatis ni directamente del pactum subjectionis. Es decir que el Estado, el Commonwealth o Leviatdn, no es ni pactum societatis ni pactum

fundamento nel pactum...", Mario D'Addio, L'Idea del Contratto sociale dai sofisti alla Riforma e il "De Principatu" di Mario Salamonio, p. 112, Milán, 1954.

24 Ibid., p. 25.

25 Ibid., p. 24. En otro pasaje dice D'Addio más explícitamente: "Il Salamonio... riduce la Civitas (società politica) a societas civilis, ossia alla societas di diritto privato e quindi a mera associazione di individui e può affermare, per tal motivo, che anche la prima comé la seconda, ritrova il suo fondamento... nell'accordo degli associati che si concretizza nei patti e nelle convenzioni.

I patti di questo genere non sono altro che le leggi fondamentali della cità...; in tal modo non si obbliga la societd̀ verso se stessa, ma i soci l'un verso l'altro: Neque societas sibimet obligatur sed ipsi inter se socii. Con questa affermazione il Salamonio perviene a formulare il pactum societatis in termini di individuo: la società politica ha a suo fondamento la volontà dell'individuo che per mezzo del contratto sociale si impegna con $i$ suoi simili a rispettare le regole fondamentali della vita associata", ibid., pp. 64-65. Cf. asimismo, Frédérich Atger, Essai sur l'Histoire des Doctrines Du Contrat Social, pp. 105-106. Montpellier, 1906.

26 No obstante la unanimidad que reina sobre esta unidad, un cuestionamiento de la misma también es posible, como lo demuestra Georg Koch en su libro sobre Manegold de Lautenbach:

Von einer "Uebertragung der Staatsgewalt" bei der Erhebung eines Königs kan korrekterweise nur dann geredet werden, wenn ein Staat und eine Staatsgewalt schon 
subjectionis. Él es la resultante indirecta, el tercero, al que los individuos contratantes han convenido entre sí a obedecerle incondicionalmente, sin que este tercero sea responsable ante ellos. Del pactum societatis se produce eso que se llama soberanía. ${ }^{27}$ Esa soberanía es encarnada en Locke por la community, y en Rousseau por le peuple. En Hobbes, esa soberanía, que tanto en Locke como en Rousseau es inalienable, es transferida al Leviatán. Esa transferencia es una alienación completa, similar en sus consecuencias a la "translatio imperii" de la disputa medieval. El Estado hereda en Hobbes las características tradicionales de la monarqufa absoluta. La diferencia en Hobbes es que esas caracteristicas son adquiridas por el Estado o el Leviatán no por gracia de Dios o por derecho divino, sino por vía contractual, por consenso popular, por decirlo así. (Esto explica por qué Locke no ataca a Hobbes, sino a Robert.

vor dieser Handlung bestanden. Dies ist auch die Auffassung der späteren staatsrechtlichen Systeme, wenn sie im allgemeinen dem Herrschaftsvertrage, sei es zeitlich oder nur logisch, den eigentlich staatsbegründenden Gesellschaftsvertrag vorausgehen lassen. Der Gesellschaftsvertrag schafft erst mit dem Staate die Staatsgewalt, die dann von der Gesamtheit auf einen einzelnen übertragen wird. Wie steht nun Manegold $z u$ dieser später geläufigen Theorie? Kennt auch er eine Staatsgewalt, die schon vor seinem Herrschafts-und Unterwerfungsvertrage bestand und im Volke, der organisierten Gesellschaft, ruhte? Die Frage ist nicht müssig; denn an sich ist wohl denkbar, dass nicht ein vorheriger Gesellschaftsvertrag, sondern der Herrschaftsvertrag erst den Anfang des Staates bedeutet. Dann kann nicht die Rede sein von einer "Uebertragung” der Staatsgewalt vom Volke auf den König; denn der Vertrag zwischen Volk und $K \delta n_{i g s c h}$ af $t$ erst eine Staats gewalt. Dorher gab es nur ein Nebeneinander souveräner Individuen, durch den Herrschaftsvertrag, den jedes dieser Individuen mit dem König eingeht, wird die Gewalt über alle in eine Hand gelegt, eine einheitliche Gewalt, die Staatsgewalt, geschaffen; mit der Vernichtung, des vertrages, genauers der Verträge, verschwindet diese einheitliche Gewalt, das Volk löst sich wieder in seine Atome, in Individuen auf. Bei einer solchen Betrachtung fält also Herrschaft und Staat, Herrschaftsvertrag und Staatsvertrag zusammen, während nach der späteren, an antike Vorbilder anknüpfenden Theorie nur der Gesellschaftsvertrag notwendig ist zur Staatsgründung, Georg Koch, Manegold von Lautenbach und die Lehre von der Volkssouveränität unter Heinrich IV, pp. 54-55. Berlin, 1902.

27 En el estado de naturaleza habfa sólo individuos. Estos individuos, en cuanto libres e iguales, eran soberanos. En su calidad de soberanos cerraron los individuos el Contrato Social, lo que implicaba una renuncia a la soberanía individual, renuncia que, por la condición de libres e iguales de los individuos renunciantes, no podía ser sino voluntaria. De los individuos se formó entonces el pueblo, entendido éste como una categoría jurídico-política, como Estado, resultante del consensus iuris de los contratantes. (Más tarde adquirirá ese Estado una personalidad propia o Staatspersönlichkeit.) El pueblo, así constituido, adquiere la soberanía que tenían antes los individuos, todos y cada uno de ellos. Así resulta pues la soberanía popular o soberanía del pueblo, "la souveraineté du peuple".

El resultado de todo esto en conexión con la revolución será, que aun cuando sea esgrimida la defensa de los Derechos humanos y de los Ciudadanos, los derechos de los individuos pues, para justificar la revolución, ésta no es legitimada por la soberanía de los individuos, sino por la soberanía del pueblo. Esto no puede ser de otra manera, por lo demás, ya que la revolución no acontece en el estado de naturaleza, el reino de los individuos soberanos, sino en el Estado ya constituido. 
Filmer). Este sesgo fue evidentemente moderno. En efecto, Hobbes fortalece la monarquía absoluta o absolutista, dándole una base democrática. En este sentido debe verse también el que Hobbes no piense solamente en un regente o monarca como el agraciado con la autoridad soberana, sino también en una asamblea. Esto último implicaba sin duda una inconsecuencia teórica por parte de Hobbes. Rousseau escapará a esa inconsecuencia mediante la radicalidad de la volonté générale. También un absolutismo ("...l'aliénation totale de chaque associé avec tous les droits à toute la communauté... Comme la nature donne a chaque homme un pouvoir absolu sur tous ses membres, le pacte social donne au corps politique un pouvoir absolu sur tous les siens..."), ${ }^{28}$ que, por el carácter abstracto de la voluntad general, es más implacable que el absolutismo del Leviatán. Pues al fin $\mathrm{y}$ al cabo el Leviatán tenía características de ser viviente, era por lo menòs un "Artificial Man", un "homo artificialis", y no una mera abstracción como la volonté générale. Hobbes, pues, neutraliza políticamente el pactum subjectionis.

\section{El aspecto histórico del pactum subjectionis}

$\mathrm{Y}$ es que, contrariamente al pactum societatis, había sido el pactum subjectionis el que había servido por siglos de fuente directa o indirecta del ius resistentiae, del derecho a la resistencia. Y cuando se hablaba del Contrato Social se entendía por éste por regla general el pactum subjectionis.

El ejemplo de mayor peso en apoyo del pactum subjetionis era el extraido de la Biblia, del Viejo Testamento. El caso más político citado alli es el del pacto de David con la tribus israelitas, pacto que condujo a su unción como rey (cf. Samuel 5,1). También el Derecho Romano fue puesto al servicio del pactum subjectionis. La lex regia fue su expresión. Otro ejemplo citado con mucha frecuencia en apoyo del pactum subjectionis es el de la famosa cláusula aragonesa, en la que los señores del reino de Aragón le dicen al rey Alfonso III, en 1287: "Nos, que valemos tanto como vos y que juntos somos más que vos, os hacemos nuestro rey y señor, con tal que nos guardéis nuestros fueros y libertades, y si no, no." ${ }^{29} \mathrm{El}$ ejemplo literario más notable en la Edad Media, en apoyo del pactum subjectionis nos lo ofrece el monje Manegold de Lautenbach en su obra Liber ad Gebehardum (1083-1085), con la que interviene en la disputa de las Investiduras, en defensa de la posición del Papa Gregorio VII contra el emperador Enrique IV.

28 J.-J. Rousseau, Du Contrat Social, op. cit., I, p. 51; II, p. 68. Cf. Gierke, 1968, p. 117.

29 Fritz Kern, Gottesgnadentum und Widerstandsrecht, p. 210. Munich, 1954. 
Manegold es considerado como el primero que funda el pactum subjectionis, el Herrschaftsvertrag, en la soberanía popular. A esa conclusión llega Manegold interpretando la lex regia en un sentido contractual. ${ }^{30}$ Gough nos sintetiza las ideas más importantes de Manegold:

The'position and powers of a king, he tell us, excel all other earthly powers, so that base or wicked men are not fitted to exercise them; rather, a man who as king is to govern and have the care of all should outshine his fellows in all virtue and wisdom, and study to rule in strictest equity. The people does not exalt him above itself (neque enim populus ideo eum super se exaltat) in order to give him scope to play the tyrant, but in order that he may be a guard against the tyranny and injustice of others. So if he who is chosen (eligitur) to repress the wicked and protect the just begins to cherish wickedness in his own heart, to oppress the righteous, and to impose on his subjects the cruellest tyranny, from which it was his duty to shield them, is it not clear that he deserves to be deposed from the position that was granted to him (merito illum a concessa dignitate cadere), and that the people is free from all subjection to him, since he was the first to break the compact, in accordance with which he was set up (cum pactum, pro quo constitutus est, constet illum prius irrupisse)? Manegold then, with an apology for taking an illustration de rebus vilioribus, proceeds to his well-known simile of the swineherd: if some one hired a man to feed his pigs, and later discovered that the man instead of feeding them was slaughtering, mutilating, and distroying them, would he not dismiss him in disgrace, and refuse to pay him his wages as well? Nor is this all that Manegold has to say in condemnation of tyranny, for he returns to the subject in a later chapter. If a king violates the compact under which he is elected (si quando pactum, quo eligitur, infringit), and disturbs and confounds what it was his business to set in order, the people is justly and reasonably absolved from its allegiance, since he was the first to break that faith which bound them together (quippe cum fidem prior ipse deseruerit, quae alterutrum altero fidelitate colligavit). The people never binds itself by an oath to obey a ruler who is possessed by fury, and is under no obligation to follow such a man where. ver his madness drives him. ${ }^{31}$

El pactum subjectionis se va debilitando, sin embargo, a medida que el derecho a la resistencia va perdiendo su carácter legal, proceso que se inicia en el momento en que el partido monárquico, en reacción a su cuestionamiento en la disputa de las Investiduras, acentúa el derecho

30 Cf. ibid., pp. 216-218.

31 J. W. Gough, op. cit., pp. 29-30. 
divino de su poder. Un esfuerzo prácticamente desesperado contra esa tendencia desplegaron los monarcómacos. En efecto, retomando la bandera de la soberanía popular "charakterisirten die 'Monarchomachen' einstimmig den $\mathrm{H}$ errscher als einen vertragsmässig bestellten obersten Volksbeamten, welchem ein zwar selbständiges, aber resolutiv bedingtes Recht auf Ausübung der Staatsgewalt eingeräumt sei. Zugleich erklärten sie die Herrschergewalt für eine durch die Grenzen der Amtsvollmacht und die Rechte der Unterthanen beschränkte, an die Verfassung und die Gesetze schlechthin gebundene Machtbefugniss".32 Además, en conexión con el derecho a la resistencia, "legten sämmtliche 'Monarchomachen' das Hauptgewicht auf die von ihnen dem Volke zugeschriebene Befugnis, dem zum 'Tyrannen' gewordenen Herrscher gewaltsam zu widerstehen, über ihn Gericht zu halten und erforderlichen Falls ihn abzusetzen und zu bestrafen..." ${ }^{33}$ En cuanto al criterio para determinar o definir la tiranía, los monarcómacos lo tenían claro (como también era clara la proveniencia: Santo Tomás de Aquino): "Man lehrte, dass der legitime Herrscher durch die Verletzung seiner Amtspflicht zum Tyrannen werde; dass gegen einen solchen 'tyrannus quoad exercitium' allerdings, während gegen den 'tyrannus quoad titulum' Jedem Alles erlaubt sei, dem einzelnen Privaten nur das Recht des passiven Widerstandes zustehe; dass dagegen die unteren Magistrate zum Schutze der ihnen anvertrauten Bevölkerung seinen tyrannischen Massregeln aktiv und im Nothfall bewaffnet zu widerstehen befugt wie verpflichtet seien; dass endlich das Volk selbst durch seine Repraesentantenversammlung und in deren Ermangelung in unmittelbarer Versammlung über ihn Gericht zu halten, ihn zu korrigiren, erforderlichen Falls ihn abzusetzen und zu strafen, ja, ihn zu tödten oder als öffentlichen Feind für vogelfrei zu erklären das Recht habe. Für den Fall einer Verhinderung dieses ordnungsmässigen Verfahrens durch die Gewalt des Herrschers oder die Pflichtwidrigkeit der Majorität der Volksrepräsentanten gieng diese Doktrin bei der Mehrzahl ihrer Vertreter in den mehr oder minder unzweideutigen Aufruf zur Revolution, bei $M$ aria $n$ a in die Empfehlung des Tyrannenmordes über..." ${ }^{4}$

El proceso del resquebrajamiento del pactum subjectionis es acelerado en el Renacimiento, del cual dice Gough: "... the whole medieval fabric was shattered, and in its place there arose the independent, territorial state, ruled by the sovereign, territorial monarch, whose will was

32 O. v. Gierke, Johannes Althusius und die Entwicklung der naturrechtlichen Staats Theorien, pp. 144-145 (Reprint). Aalen, 1968.

38 Ibid., p. 145.

34 Ibid., p. 146. 
law". ${ }^{35}$ Ese resquebrajamiento del pactum subjectionis como fuente legal del derecho a la resistencia se completa en el siglo xvir con el coronamiento del absolutismo: "Vom 17.Jahrhundert an, dem Beginn des Zeitalters des Absolutismus", nos dice Karl Friedrich Bertram, "verschwand das Widerstandsrecht in Deutschland aus dem positiven Staatsrecht. Die im Ständestaat zwischen Herrscher und Ständen geteilte Staatsgewalt erschien jetzt als eine einheitliche, unteilbare, in der Person des Herrschers zusammengefasste höchste Gewalt. Der Herrscher erschien berechtigt, sich über das im Staate geltende Recht, über Vereinbarungen mit den Ständen und über Privilegien aller Art hinwegzusetzen, wenn dies aus Gründen der Staatsnotwendigkeit, über deren Vorliegen er allein entscheiden konnte, unumgänglich notwendig war. Der Untertan hatte dem Herrscher unbedingten Gehorsam zu leisten; diese Gehorsamspflict war nicht mehr an die Bedingung der Beachtung des geltenden Rechts und der bestehenden Vereinbarungen gebunden. Gegenüber einer solchen Staatsauffassung war ein Widerstandsrecht schon begrifflich ausgeschlossen..." 36

En la teoría política, ese proceso tiene por límites a Hobbes. Pues si bien es cierto que él concibe el pactum subjectionis, en la forma ya indicada, como fuente del poder político, su carácter contractual, de obligaciones reciprocas, sobre todo del monarca frente al pueblo, cesa una vez constituido el poder polftico o Leviatán. (Rousseau habrá de eliminar el pactum subjectionis por una razón contraria a la de Hobbes, a saber: para no concederle ningún derecho al monarca frente al pueblo.) La soberanía del poder político es la resultante de la alienación total de la soberanía de los individuos en particular y del pueblo en general. Sobre esto dice Otto v. Gierke: “... So ergibt sich diese allumfassende, unumschränkte und unverantwortliche Herrschergewalt, welche Persönlichkeit, Eigentum, Recht, Gewissen und Religion der Unterhanen absorbit, durch kein Gesetz, keinen Vertrag und keine Pflicht gebunden wird und keinen anderen Richter als sich selbst kennt ..." ${ }^{37}$ Por cierto que ese absolutismo del soberano (personal) en Hobbes, se lo aplica Rousseau al pueblo soberano. Sobre esto nos dice el mismo Gierke: “... im Gegensatz zu seinen Vorgängern erklärt Rousseau die Volkssouveränität, indem er auf sie den Souveränitätsbegriff der Absolutisten überträgt, zugleich für vollkommen, unbeschränkt und unbeschränkbar, für schlechthin an kein Gesetz und keine Verfassung gebunden und selbst der Ausübung nach für unïbertragbar...". ${ }^{38}$ Por cierto

35 J. W. Gough, op. cit., p. 36.

36 Karl Friedrich Bertram, Widerstand und Revolution, pp. 27-28. Berlin, 1964.

37 Otto v. Gierke, op. cit., p. 176.

38 Ibid., p. 202. 
que esa concepción radical de la soberanía popular da lugar a que se hable en Rousseau de la revolución permanente: "...aus der allein aufrecht bleibenden schrankenlosen Machtvollkommenheit der mit ihrem blossen Zusammentritt alle konstituirten Gewalten und die ganze bestehende Verfassung zu Boden legenden Volksversammlung entwikkelte er sein Programm der permanenten Revolution". ${ }^{38}$

\section{El Contrato Social y la revolución}

Pero al mismo tiempo que llega a su término el pactum subjectionis como fuente del derecho a la resistencia, al mismo tiempo que cesa éste como Rechtsbehelf (Bertram), como instrumento legal de derecho positivo, insurge el pactum societatis como fuente de un "derecho" más radical, del derecho a la revolución, transformado en instrumento legitimo de derecho natural.

Esa necesidad de legalidad en el caso del derecho a la resistencia y de legitimidad en el caso del derecho a la revolución es comprensible, por lo demás, pues en ambos casos se trata de una lucha contra la arbitrariedad (del poder político).

John Locke es el pensador que le da esa forma revolucionaria al pactum societatis, compact o Contrato Social. Haciendo abstracción del Estado real, haciendo de éste tabula rasa, se traslada Locke a un estado de naturaleza, no completamente primitivo, sino pre-estatal, por tener vigencia en él un orden juridico de base natural: "The state of nature has a law of nature to govern it which obliges every one...".40 Ese estado de naturaleza no es un estado donde las pasiones dominan, donde predomina la parte concupiscente del alma, como afirma Hobbes, sino un estado donde gobierne la razón. ${ }^{41}$ No es un estado de guerra, sino un estado de paz. ${ }^{42}$ Siendo la condición principal de ésta que en ese estado "all the power and jurisdiction is reciprocal...".43

Salir de un tal estado voluntariamente es incomprensible a primera vista. De ahí que Locke incida sobre ello:

If Man in the state of nature be so free, as has been said, if he be absolute lord of his own person and possessions, equal to the greatest, and subject to nobody, why will he part with his freedom, why

39 Jbid., p. 92.

40 John Locke, Two Treatises of Government, Chapter II, 6, p. 123. The Hafner Library of Classics. Nueva York y Londres, 1966.

41 Ibidem.

42 Ibid., p. 122.

43 Ibidem. 
will he give up his empire and subject himself to the dominion and control of any other power? La respuesta de Locke es convincente: To which it is obvious to answer that though in the state of nature he hath such a right, yet the enjoyment of it is very uncertain and constantly exposed to the invasion of others; for all being kings as much as he, every man his equal, and the greater part no strict observers of equity and justice, the enjoyment of the property he has in this state is very unsafe, very unsecure. This makes him willing to quit a condition which, however free, is full of fears and continual dangers; and it is not without reason that he seeks out and is willing to join in society with others who are already united, or have a mind to unite, for the mutual preservation of their lives, liberties, and states, wich I call by the general name "property". ${ }^{44}$

Es claro que sólo las ventajas podían hacer que se tomara una decisión semejante. No acciones compulsivas. Como los hombres se definían todos como libres, iguales e independientes, sólo el propio consentimiento podía producir el cambio del status. ${ }^{45}$ Así se lleva a cabo, pues, el Contrato Social constitutivo de la sociedad y del Estado, de la civil society o political society.

Esa sociedad civil o Estado es, como ya hemos visto, el pueblo, fuente del poder político soberano.

$\mathbf{Y}$ como el pueblo, aunque soberano, no ejerce inmediatamente esa soberanía (Rousseau diría: toda esa soberania), por eso crea al Gobierno: ${ }^{40}$ la legislatura y el ejecutivo, según Locke, el ejecutivo solamente, según Rousseau. Ese Gobierno no es el producto de un pacto especial entre los gobernados y los gobernantes (es el mismo caso de Hobbes). Sino que es una delegación (o comisión) de su poder que hace la com, munity o el pueblo. En términos medievales podría hablarse de una simple "concessio imperii". Delegación, no alienación, como en el caso de Hobbes, y por tanto recuperable. Esto sucede cuando el Gobierno hace mal uso del poder que el pueblo le ha confiado, cuando no lo

44 Ibid., p. 184.

45 Ibid., p. 168.

46 "Indem er jedoch den Inhalt der Souveränität ausschliesslich in die Gesetzgebung als allgemein gefassten Ausspruch des allgemeinen Willens verlegt un die Vollstreckung der Gesetze als eine auf das Besondere gerichtete und nothwendig abhängige Thätigkeit dem Souverän ausdrücklich abspricht und einem damit beauftragten nichtsouveränen Subjekte zuweist, schafft er sich trotzdem die Möglichkeit, nicht nur die Einsetzung einer Regierung als wesentliches Erforderniss des Staates zu behaupten sondern auch dem Regierungskörper eine eigne moralische Persönlichkeit, ein reelles obschon nur geliehenes Leben und eine mindestens relativ selbständige Macht gegen die Einzelnen zuzuschreiben und so aus der von ihm mit Nachdruck verworfenen Lehre von der Gewaltentheilung die für seine Doktrin brauchbaren Gedankenelemente zu entlehnen", Gierke, ibid, p. 203. 
ejerce un beneficio del bien público, de la sociedad. En este caso, el pueblo se ve obligado a hacer un "appeal to heaven", a invocar al cielo a hacer la revolución. Asi, ese poder "reverts to society, and the people have a right to act as supreme and continue the legislative in themselves, or erect a new form, or under the old form place it in new hands, as they think good". 47

Con esto está diciendo Locke que la revolución no implica una recaída en el status naturalis, menos aún en uno en sentido kantiano, ${ }^{48}$ que la disolución del Gobierno no implica necesariamente una disolución de la sociedad. Lo contrario sí es cierto en todo caso: "Whenever the society is dissolved, it is certain the government of that society cannot remain". ${ }^{48}$

Por cierto que según el propio Locke, el derrocamiento de un tal gobierno, que abusa de la confianza depositada en él, que quiere hacer de la fiducia ("trust") un derecho adquirido, puede ser considerado más bien como una disolución automática de sí mismo, que como una revolución. ${ }^{50}$ Esta conclusión es lógica también desde el punto de vista de la teoría contractual como pactum societatis, tanto en Locke como en Rousseau. En efecto, como la constitución de la sociedad civil precede al gobierno, como éste no es el producto de un pacto o contrato entre gobernados y gobernantes como sucede teóricamente en el caso del pactum subjectionis, sino que es el producto de la decisión del pueblo ya constituido, una delegación de éste a uno o varios hombres de su confianza, que harán simplemente de fiduciarios del pueblo (Locke) o de oficiales (Rousseau), entonces no puede darse un enfrentamiento entre pueblo y gobierno como partes en igualdad de derechos y de deberes. Pero, ya lo hemos insinuado: una cosa es la lógica del Contrato Social y otra la del Estado real o la del gobierno establecido. Estas lógicas opuestas son el reflejo de intereses opuestos, generadores del conflicto, de la revolución.

El hecho de que en el pactum societatis no se enfrenten pueblo y gobierno como partes contratantes, como es el caso en el pactum subjectionis, no quiere decir que la revolución sea menos explosiva en virtud del primero que en virtud del segundo. Al contrario. Y es que del Con-

47 J. Locke, ibid., p. 247. (Chapter XIX. Of the dissolution of government.)

48 Kant considera el status naturalis negativamente, acentuando el aspecto juridico sobre el aspecto social. La razón de ello es su concepción de la sociedad como sociedad civil, es decir, como implicadora del Estado. Así, la revolución al destruir el Estado, destruye también la sociedad, dando lugar a un status naturalis negativo, diferente al de Locke, es decir, como un estado donde reina una libertad salvaje, carente de todo orden legal.

49 Ibid., p. 229.

50 J. W. Gough, op. cit., p. 144. 
trato Social, sobre todo en el sentido de Rousseau, emana la soberanía popular, fuente de todos los poderes particulares y del poder en general. En segundo lugar, el Contrato Social está sostenido por un derecho considerado originario, a saber, el Derecho Natural, del que se deriva el Derecho Civil, como se deriva la sociedad civil del estado de naturaleza o estado pre-estatal. Sabiéndose legitimada en forma tan originaria, la revolución es necesariamente radical, en un doble sentido: en cuanto que dirige su acción a las raíces de la sociedad y del Estado y en cuanto que es ajena a compromisos. Lo malo es, y eso aumenta la explosividad de la revolución, que el Estado real olvida su origen contractual. En efecto, el Estado, de manera decisionista (Carl Schmitt), se considera a sí mismo como originario, como la fuente del único derecho válido, como aunando en sí derecho y ley, justicia y legalidad, legalidad y legitimidad. ${ }^{51}$ Así, el Estado le niega a la revolución la legitimidad por falta de legalidad. ${ }^{52}$

La cuestión de la legitimidad o legitimación de la revolución tiene el carácter de problema permanente. Fritz Kern insinúa un compromiso: “...das positive Staatsrecht ist nicht von unbedingtem, sondern vergänglichem Wert und die Revolution hat sich zuweilen als berfreiende und notwendige Zwangsmacht erwiesen. Doch vermochte sie dies am sichersten dann, wenn sie den Anschein, selbst Recht zu sein, völlig abstreifte. Alles Recht aber muss sie ins Schwanken bringen, wo sie selbst sich ihm gleichstellt...".5s

Fritz Kern no está de acuerdo, pues, con un derecho a la revolución expressis verbis. $\mathrm{Y}$ como no está de acuerdo, cita con asombro el caso del parágrafo 35, el "enfant terrible" de la Constitución revolucionaria francesa de 1973:

...Quand le gouvernement viole les droits du peuple, l'insurrection est, pour le peuple et pour chaque portion du peuple, le plus sacré des droits et le plus indispensable des devoirs. ${ }^{54}$

¿Pero cómo podría carecer de derecho lo que es fuente de derecho? Si la revolución hubiera de acontecer en ei estado de naturaleza, esa pre-

51 Cf. Carl Schmitt, Legalität und Legitimität, p. 22. Munich, 1932.

52 "Für den Begriff der Legalität ist geschichtlich und begrifflich zu beachten, dass er eine Angelegenheit und ein Problem des parlamentarischen Gesetzgebungsstaates und der ihm spexifischen Art Normativismus ist. Er übernimmt die vom fürstlichen Absolutismus geschaffene Situation, nämlich die. Beseitiguing jedes Widerstandsrechts und das "grosse Recht" auf unbedingten Gehorsam; aber er gibt ihm die Weihe der Legalität, die er durch seine generellen, vorher bestimmten Normierung schafft", ibid., página 15.

53 Fritz Kern, op. cit., p. 208.

54 Ibid., p. 209. 
gunta holgaría. Pero donde ella se lleva a cabo es en el Estado, y es, además, contra éste que ella se lleva a cabo. Es comprensible pues que el Estado, el orden legal establecido, vigente, no quiera legitimar la acción de su victimario. "Schon ihrem Wesen nach", dice el jurista Bertram, "kann keine Verfassung und keine Rechtsordnung ihre gewaltsame Beseitigung zulassen". ${ }^{55}$

Un inconveniente tiene eso. Como a la revolución no se le concede el derecho que se le concedió en un tiempo a la resistencia, como no es legitimada por el Estado para imponer sus ideas, para reedificar el edificio de la sociedad y del Estado, se ve obligada a tomar el camino de la ilegalidad. Por eso "ist die Revolution rechtswidrig und die Handlungen der Revolutionäre sind Unrecht". ${ }^{56}$

Y precisamente por la radicalidad de la revolución, por su tendencia a eliminar violentamente el orden constitucional y estatal, por eso los juristas consideran que cumple el "strafrechtlichen Tatbestand des Hochverrats" ${ }^{57}$ Como el más grave delito en el Estado, como el peor de los crímenes, así es calificada la revolución por los juristas.

Pero como la revolución no destruye por destruir, como ella es creadora, fuente de derecho, y es fuente de derecho por ser su propio origen el derecho, no el positivo, pero sí el natural, por eso se ha dado el caso de su defensa por uno que otro jurista, sobre todo por el jurista C. A. Emge: "Revolution ist ein Titel illegitimer Rechtsentstehung. Das bedeutet für die beteiligten Rechssysteme, dass die revolutionären Handlungen zwar rechtswidrig sind im Hinblick auf das frühere Recht, jedoch notwendig nicht rechtswidrig für das neue durch sie geschaffene". ${ }^{58}$

Ese juicio de Emge no hizo escuela, sin embargo. En Bertram leemos el criterio en contra, el aceptado en términos generales: "Selbst wenn man unterstellt, dass die Revolution eine legitime Art der Rechtsentstehung ist, so bestimmt sich doch die Rechtswidrigkeit der Revolution und der ihr zugrunde liegenden Handlungen genau wie bei Handlungen anderer Straftatbestände grundsätlich nach dem Recht, welches zur Zeit der Tat gilt". ${ }^{59}$ Esto es así aun en el caso de que triunfe la revolución. Pero ¿cómo, se preguntará, qué va a ser entonces de los revolucionarios victoriosos? ¿Se les hará el proceso por alta traición? ¿Y quién les va a hacer el proceso si ellos están ahora al frente del nuevo Estado, si ellos son los nuevos gobernantes? Para los juristas la cuestión es clara: " $D a$

55 K. F. Bertram, op. cit., p. 73.

56 Ibidem.

57 Ibidem.

58 C. A. Emge, Revolutionäres Uebergangsrecht, en Deutsche Juristen-Zeitung, 2. Jahrg. 1919, Heft $5 / 6$.

59 K. F. Bertram, op. cit., p. 73. 
(die Strafverfolgung) allein dem Staat zusteht, kann er auch von ihr absehen, sei es auf Grund einer Amnestie, sei es einfach unter Bruch des Legalitätsprinzips".60 Ahora bien, en caso de amnistía, ¿quién la decretaría? ¿Los propios "delincuentes" que son ahora los órganos del Estado? Juez y parte se sería entonces. A un exabrupto semejante conduce el formalismo en el Derecho. Por supuesto que un tal dilema no se les presenta a los revolucionarios victoriosos. Mas, como tampoco se van a castigar a șí mismos los nuevos gobernantes por haber llevado a cabo una revolución exitosa, entonces, según la lógica jurídica formal, el nuevo Estado se estrenaría con el delito de la violación del principio de la legalidad.

Pero la revolución no tiene en verdad por qué preocuparse por lo que piensen de ella los juristas. Tampoco tiene por qué andar a la búsqueda desesperada de una legitimación. La revolución se legitima a sí misma. Su propia acción, en la que se realiza, es su verdadera legitimidad. Esto no es, empero, un acto decisionista de la revolución. Ella tiene antes bien su fundamento en un Derecho originario o, como dice Locke, " $a$ law antecedent and paramount to all positive laws of men". Ese Derecho originario que legitima al pueblo "to make their appeal to heaven", ${ }^{11}$ es el Derecho Natural.

A decir verdad, la revolución ni siquiera necesita irse a un estado de naturaleza, pre-estatal, en busca de su legitimación. Esa legitimación la puede tener de manera más inmediata de su propio sujeto. Ese sujeto de la revolución es, según Kant, el pueblo. Y como el pueblo, en cuanto creación del Contrato Social, encarna la soberanía (Rousseau), y como ésta en el Estado es la verdadera fuente del Derecho, no hay entonces legitimidad más originaria que la de la revolución.

Esta es la realidad, radical, originaria, que no deben perder de vista los gobernantes. Pues si la pierden de vista, entonces el pueblo, que es uno con el Estado (Rousseau), se las recuerda mediante la revolución: "... les dépositaires de la puissance exécutive", dice Rousseau, " $e$ e sont point les maîtres du peuple mais ses officiers, qu'il peut les établir et les destituer quand il lui plaît, qu'il n'est point question pour eux de contracter mais d'obéir et qu'en se chargeant des fonctions que l'État leur impose ils ne font que remplir leur devoir de citoyens, sans avoir en aucune sorte de droit de disputer sur les condicions". ${ }^{62}$

60 Ibid., p. 74.

61 J. Locke, op. cit., p. 207 (Of Prerogative).

62 J. J. Rousseau, Du contrat social, pp. 139-140. 


\section{Conclusión}

A manera de introducción a un pensamiento de Fichte sobre la revolución en conexión con la teoría contractual, dice el jurisconsulto Georg Jellinek:

So ist die Vertragstheorie, logisch zu Ende gedacht, nicht staatsbegründend, sondern staatsauflösend. ${ }^{68}$

Con el mismo derecho podría decirse, sin embargo, en un sesgo positivo, que la teoría contractual o teoría del Contrato Social, es "staatsauflösend, um staatsbegründend sein zu können", que disuelve un Estado viejo para fundar uno nuevo.

La tendencia a cuestionar la legitimidad de la revolución ha conducido a algunos autores a poner en entredicho la consistencia de la teoría contractual sobre la base del. Derecho Natural. El más connotado representante de esa tendencia es Jellinek. Éste dice en efecto:

Wie lange Zeit hat es gedauert, ehe der Satz von der bindenden Kraft der Verträge, der dem Naturrecht so selbstverständlich erscheint, überhaupt gefunden wurde! Dass der blosse Konsens absolut verpflichtende Kraft habe, ist überdies auch heute ein nirgends in ausnahmsloser Geltung stehender Satz. Ferner ist es unmöglich, das objektive Recht für Inhalt und Rechtsfolgen des Grundvertrages aufzuweisen... Der grösste Mangel der naturrechtlichen Begründung des Vertrages is aber die Unmöglichkeit, die absolute Bindung des Individuums durch den einmal abgegebenen Konsens zu erweisen. Ist der Mensch seinem Wesen nach frei, dann ist der Satz $R$ o us sea us unwiderleglich, dass die Freiheit unverzichtbar sei, dann kann aber das Individuum kraft dieser unverzichtbaren Freiheit auch jederzeit den Vertrag lösen...64

Pero. es que si el individuo no pudiera resolver el Contrato, la revolución sería entonces imposible. Las paradojas de Rousseau no invalidan de ninguna manera el objetivo del Contrato: la libertad del pueblo de decir "No", de tomar nuevamente en sus manos' la soberanfa, de hacer, pues, la revolución.

Con todo, Jellinek es objetivo; él no ve solamente las fallas de la teoría contractual, sino también sus aciertos:

Hat die Vertragstheorie demnach ihr Ziel verfehlt, so war und ist ihre historische Wirkung geradezu unermesslich. Der ganze moderne 63 G. Jellinek, op. cit., p. 217.

64 Ibid., p. 216. 
Staat ist in seinem Bau und seinen Institutionen von ihr auf das tiefste beeinflusst worden. An dieser Stelle sei nur kurz erwähnt, dass die Idee ausdrücklicher Freiheitsrechte, die Forderung der Errichtung des Rechtsstaates und die Erfïllung dieser Forderung durch richterliche Garantierung des gesamten, also auch des öffentlichen Rechtskreises der Individuen auf sie zurückzuführen ist. Die Grundsätze der liberalen politischen und ökonomischen Parteien sind unter ihrem tiefgreifenden Einfluss gebildet worden. Durch die enge Verbindung, in welcher sie mit der neueren Lehre von der Volkssouveränität steht, hat sie auch das Fundament für die aus deren Prinzipien abgeleiteten Folgerungen gelegt. In der französischen Plebiszitslehre, in dem schweizerischen und amerikanischen Verfassungsreferendum lebt sie ebenso fort wie in den politischen Forderungen der deutschen Socialdemokraten.' Im 18. Jahrundert unbestritten herrschend, hat sie in Europa eine alte Welt in Trümmer geschlagen und jenseits des Ozeans eine neue schaffen helfen. Denn politische Lehren, hierin den religiösen gleichend, wirken nicht durch das Mass abstrakter Wahrheit, das ihnen innewohnt, sondern durch die Stärke und Tiefe, mit der sie die Geister zu beherrschen imstande sind. ${ }^{65}$

Apéndice

Traducciones de las citas en alemán

1 "Ella (la teoría contractual, FL) toma uno o dos principios de un orden jurídico estatal existente para derivar de él el Estado, lo cual no

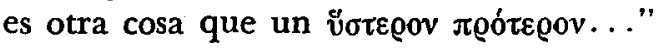

26 "Se puede hablar correctamente de una "transferencia de la autoridad estatal' en el caso de la elevación de un rey al trono sólo cuando existían antes de ese acto, un Estado y una autoridad estatal. Ésa es también la concepción de los sistemas de derecho público posteriores, al hacer preceder en general, bien sea temporalmente o sólo lógicamente, al contrato de gobierno el contrato social como el propiamente fundador del Estado. En el momento en que el contrato social crea el Estado, crea la autoridad estatal, que es transferida luego por la colectividad a un individuo. ¿Cuál es la opinión de Manegold sobre esa teoría que habría de devenir más tarde la más familiar? ¿Concibe él también una autoridad estatal que hubiera existido antes de su contrato de gobierno y de sujeción y que hubiera reposado en el pueblo, en la sociedad organizada? La pregunta no está de más porque en sí es posible pensar 
que no haya existido un contrato social original o anterior, sino más bien el contrato de gobierno originador del Estado. En ese caso no puede hablarse entonces de una "transferencia" de la autoridad estatal del pueblo al rey, pues es sólo con el contrato entre el pueblo y el rey que se crea una autoridad estatal. Antes existían solamente individuos soberanos agrupados unos al lado de otros. Mediante el contrato de gobierno, que cada uno de esos individuos cierra con el rey, es colocada en una mano la autoridad sobre todos, es creada una autoridad unitaria, la autoridad del Estado. Con la anulación del contrato, más exactamente, de los contratos, desaparece esa autoridad o poder unitario, el pueblo se disuelve en sus átomos, en individuos. Considerado eso así, se da una unidad entre gobierno y Estado, entre contrato de gobierno y contrato de Estado; mientras que según la teoría posterior, que se apoya en los modelos antiguos, sólo el contrato social es necesario para la fundación del Estado."

32 "los monarcómacos caracterizaron al unísono al soberano como un supremo funcionario del pueblo, nombrado en forma contractual, a quien le conceden, para el ejercicio del poder estatal, un derecho ciertamente independiente pero bajo condición resolutoria. Al mismo tiempo declararon el poder del soberano como restringido por los límites de la jurisdicción y de los derechos de los súbditos, poder sujeto a la constitución y a las leyes".

33 "todos los monarcómacos pusieron el acento sobre el derecho, asignado por ellos al pueblo, de oponérsele por la fuerza al soberano devenido 'tirano', de someterlo a juicio y si fuere necesario, de destronarlo y castigarlo..."

34 "(Los monarcómacos) enseñaban que el soberano legítimo devenía tirano al violar sus deberes; que contra un tal 'tyrannus quoad exercitium' los particulares tenían ciertamente un derecho a la resistencia, pero pasiva, frente al 'tyrannus quoad titulum', en cambio, todos podían actuar como quisieran; que los magistrados inferiores, por lo contrario, estaban autorizados y obligados a oponérsele activamente, $y$, si fuere necesario, armados, a las medidas tiránicas; y que finalmente, el pueblo mismo, mediante su asamblea de representantes, $o$, a falta de ésta, reunido directamente, tenía el derecho de someter (al soberano) a juicio, de corregirlo, y, si fuera necesario, de destuitirlo y de castigarlo, más aún, hasta de matarlo o de ponerlo fuera de la ley como a enemigo público. Para el caso de que este conveniente procedimiento fuera impedido por la fuerza de parte del soberano o por un comportamiento contrario al deber por parte de la mayoría de los representantes del 
pueblo, para este caso esta doctrina (monarcómaca) contemplaba, en la mayoría de sus exponentes, de manera más o menos clara, un llamado a la revolución. Mariana recomendaba para ese caso, el tiranicidio..."

36 "A partir del siglo xvir", dice Karl Friedrich Bertram, "cuando comienza la edad del absolutismo, desaparece en Alemania del Derecho Público positivo el derecho a la resistencia. El poder estatal dividido en el Estado estamental entre el monarca y los estamentos, se presentaba ahora como un poder unitario e indivisible, encarnado en la persona del monarca como el poder supremo. El monarca se sentía autorizado a desconocer el Derecho vigente del Estado, los acuerdos con los estamentos y los privilegios de todo género cuando lo consideraba necesario, por razones de Estado o personales. Los súbditos estaban obligados a obedecerle incondicionalmente al monarca, sin que ese deber de obediencia implicara un compromiso para el monarca. Ante una semejante concepción del Estado, quedaba excluido hasta conceptualmente todo derecho a la resistencia..."

37 "... Así resulta ese poder soberano total, ilimitado e irresponsable, que absorbe la personalidad, la propiedad, el derecho, la conciencia y la religión de los súbditos y no está sometido a ninguna ley, a ningún contrato y a ninguna obligación, ni conoce a otro juez que a él mismo..."

38 "... contrariamente al caso de sus predecesores, declara Rousseau la soberanía popular, encajándole el concepto de soberanía de los absolutistas, como perfecta, ilimitada e ilimitable, libre de ataduras a ley alguna y a ninguna constitución, e intransferible hasta para su ejercicio..."

39 "... (Rousseau) desarrolla su programa de la revolución permanente partiendo del único poder que ha dejado en pie, a saber: la ilimitada plenipotencia de la Asamblea Popular que con su simple reunión echa por tierra todos los poderes constituidos y la constitución existente en su totalidad..."

46 "Al colocar sin embargo el contenido de la soberanía exclusivamente en la legislación como decisión general de la voluntad general y negarle expresamente al soberano la ejecución de las leyes como una actividad dirigida a lo particular y por tanto necesariamente dependiente, comisionando para ello a un sujeto no soberano, se crea él (asi) la posibilidad, no solamente de afirmar la instauración de un gobierno 
como exigencia fundamental del Estado, sino también, de asignarle al cuerpo del gobierno una personalidad moral propia, una vida, aunque sólo prestada, real, y un poder por lo menos relativamente independiente respecto de los individuos, logrando así extraer de la doctrina de la división de poderes, rechazada por él con firmeza, los elementos conceptuales de utilidad para su propia doctrina."

52 "En relación con el concepto de la legalidad hay que tomar en cuenta tanto históricamente como conceptualmente, que él es un asunto y un problema inherente al Estado legislador y a la especie de normativismo que le es peculiar. Él hereda la situación creada por el absolutismo real, a saber, la eliminación de toda clase de derecho a la resistencia y el 'gran derecho' a la obediencia incondicional; pero él le da la santificación de la legalidad creada mediante la normatividad general determinada con anterioridad."

53 “... el Derecho Público positivo no tiene un valor incondicional, sino transitorio, y la revolución ha llegado a revelarse a veces como un poder liberador y necesariamente coercitivo. Mas, lo logra con mayor seguridad cuando no quiere ser ella misma derecho. $Y$ es que la revolución que quiere equipararse con el propio Derecho, termina conmoviendo los cimientos de éste..."

55 "Por su esencia misma", dice el jurista Bertram, "no puede ninguna constitución ni ningún orden jurídico permitir su eliminación violenta."

56 (Por eso "es la revolución contra derecho e injustas las acciones de los revolucionarios".

57 "el delito punible de alta traición".

58 "La revolución es un título de nacimiento ilegítimo del Derecho. Eso significa, para los sistemas jurídicos implicados, que las acciones revolucionarias son en verdad contra derecho en relación al Derecho anterior, pero no son $n^{e}$ cesariamente contra derecho para el nuevo Derecho creado por ella."

59 "Aun suponiendo que la revolución es una forma legítima de nacimiento del Derecho, la ilegalidad de ella y la de las acciones que la sustentan, es determinada exactamente como en los casos de otros hechos delictivos: en principio por el Derecho vigente en el momento de la acción."

60 "Dado que la persecución del delito es exclusividad del Estado, 
éste puede prescindir también de ella, bien sea por medio de una amnistía, o simplemente mediante violación del principio de la legalidad."

63 "Así, la teoría contractual, pensada lógicamente a fondo, no funda al Estado, sino que lo disuelve."

64 "¡Cuánto tiempo tuvo que transcurrir para que pudiera nacer la idea de la fuerza obligante de los contratos, que al Derecho natural le parece tan comprensible de suyol Que el simple consenso tenga una fuerza absolutamente obligante, es una proposición que no tiene tampoco hoy, por lo demás, por doquiera una validez sin excepción. Es además imposible que el Derecho objetivo pueda ser puesto de garantía del contenido y las consecuencias legales del contrato... El defecto mayor de la fundamentación iusnaturalista del contrato es, sin embargo, la imposibilidad de demostrar el compromiso absoluto del individuo por el consenso expresado una vez. Si el hombre es libre por esencia, entonces no puede ser refutada la idea de-Rousseau según la cual la libertad es irrenunciable; pero, en ese caso, el individuo no puede resolver el contrato cuando lo quiera en virtud de esa libertad irrenunciable..."

65 "Si la teoría contractual ha fallado según eso su objetivo, su efecto histórico ha sido y es no obstante' inmenso. Todo el Estado moderno ha sido influido profundamente por ella tanto en su edificación como en sus instituciones. Sea mencionado en este sitio todo lo que es atribuible a ella: la idea de los derechos expresos originados en la libertad, la exigencia del establecimiento del estado de derecho y el cumplimiento de esa exigencia mediante la garantización judicial de todo el ámbito legal de los individuos. Los principios políticos y económicos de los partidos liberales se formaron bajo su influencia profunda. Mediante la ligazón estrecha en que está con la moderna teoría de la soberanía popular, colocó ella también el fundamento para las consecuencias derivadas de sus principios. En la teoría plebiscitaria francesa, èn el referéndum constitucional suizo y americano, así como en los postulados políticos de los socialdemócratas alemanes, continúa viviendo ella. Cuando tenía en el siglo xviri un predominio indiscutido, hizo añicos en Europa un viejo mundo y ayudó a crear uno nuevo en ultramar. Pues doctrinas políticas, similar en ello a las religiosas, ejercen un efecto, no mediante la medida de su verdad abstracta, sino mediante la intensidad y la profundidad con que son capaceside dominar los espíritus." 